\title{
Memória: um dado criado? Uma leitura das histórias em quadrinhos do Superman
}

\author{
Edvaldo Correa Sotana ${ }^{1}$ \\ Natalia Aparecida Tiezzi Martins dos Santos ${ }^{2}$
}

\begin{abstract}
Resumo
Este artigo tem por objeto de estudo a relação entre memória e história, a partir de alguns excertos de bandas desenhadas entre 1958 a 1981 do personagem Superman. Assim objetiva tratar das características que constituem o personagem octagenário, concebendo as histórias em quadrinhos como fontes históricas. E, desta forma, explicitar o surgimento das historietas do personagem, bem como o contexto histórico que as engloba. Por fim, apresentar e analisar os excertos supracitados, estabelecendo relações pontuais entre o material pesquisado e o conceito de memória.
\end{abstract}

\section{Palavras-chave}

História; Memória; Superman.

\section{Abstract}

This article aims to study the relation between memory and history, from some excerpts from comic strips between 1958 to 1981 of the character Superman. Thus it aims to deal with the characteristics that constitute the octagenarian character, designing the comics as historical sources, and in this way to make explicit the appearance of the comic strips of the character, as well as the historical context that encompasses them, and finally to present and analyze the excerpts above, establishing relations between the material researched and the memory.

\section{Keywords}

History; Memory; Superman.

\footnotetext{
${ }^{1}$ Doutor em História (FCL-UNESP/Assis). Professor Associado do Departamento de História (IGHD/UFMT). edsotana11@gmail.com

${ }^{2}$ Mestranda da Universidade Estadual de Mato Grosso do Sul. nataliatiezzi@gmail.com
} 


\title{
VOZES $_{\text {\&IÁLORO }}^{\mid}$
}

Itajaí, v. 18, n. 02, jul/dez 2019

\section{Recordar é viver...}

Não despropositadamente, nos desenhos e histórias em quadrinhos (HQs) há vários personagens que possuem o poder de apagar, bloquear, alterar, transferir, armazenar, absorver, criar, implantar ou restaurar a memória. A título de exemplo, podese citar Mnemosine na Mitologia Grega, Cable, Charles Xavier, Jean Grey e Mesmero na Marvel Comics, Gowther em The Seven Deadly Sins, Mewtwo em Pokémon e o Caçador de Marte, Miss Marte e Superman em DC Comics ${ }^{3}$. Tais registros permitem inferir que o medo de se esquecer o que foi vivido assombra a humanidade. De acordo com as formulações de Jacques Le Goff (1990, p. 425):

\begin{abstract}
Ainda é mais evidente que as perturbações da memória, que, ao lado da amnésia, se podem manifestar também no nível da linguagem na afasia, devem em numerosos casos esclarecer-se se também à luz das ciências sociais. Por outro lado, num nível metafórico, mas significativo, a amnésia é não só uma perturbação no indivíduo, que envolve perturbações mais ou menos graves da presença da personalidade, mas também a falta ou a perda, voluntária ou involuntária, da memória coletiva nos povos e nas nações que pode determinar perturbações graves da identidade coletiva.
\end{abstract}

A lembrança pressupõe o esquecimento de algo, de outrem - mesmo que inconscientemente - pois, se de um lado, recordar é viver; esquecer também o é, como expressou Quintana nos versos acima: "Essa lembrança... mas de onde? de quem? Essa lembrança talvez nem seja nossa, mas de alguém que, pensando em nós, só possa mandar um eco do seu pensamento... Ai! Tão perdida que nem se possa saber mais de quem!”. Assim, pensando com Le Goff (1990, p. 547-8):

O documento é uma coisa que fica, que dura, e o testemunho, o ensinamento (para evocar a etimologia) que ele traz devem ser em primeiro lugar analisados desmistificando-lhe o seu significado aparente. O documento é monumento. Resulta do esforço das sociedades históricas para impor ao futuro - voluntária ou involuntariamente determinada imagem de si próprias. No limite, não existe um documento-verdade. Todo o documento é mentira. Cabe ao historiador não fazer o papel de ingênuo.

Como um agir histórico, o ato de recordar, traduz-se como um ato de alteridade, no sentido de que "ninguém se recorda exclusivamente de si mesmo, e a exigência de fidelidade, que é inerente à recordação, incita ao testemunho do outro (...)" (CATROGA, 2001, p. 45). Tanto as HQ's quanto a História estão articulando imaginários e perspectivas

${ }^{3}$ MANIPULAÇÃO da Memória, 2014. Disponível em: <https://bit.ly/327Gd6g>. Acesso: dez-2018. 


\section{VOZES $_{\text {\&DÁLORO }}^{\mid}$}

Itajaí, v. 18, n. 02, jul/dez 2019

sobre determinados contextos e questões. Dessa forma, cabe ao historiador "ir aos arquivos, isto é, deve mergulhar nas profundezas de uma época. Ele deve "passar e repassar o rio dos mortos", transgredir deliberadamente a fronteira passado/presente" (HARTOG, 2011, p. 224). Assim, História em Quadrinhos (HQ) como um documento ${ }^{4}$ e a História como uma narrativa constituem-se por meio de representações da realidade. Logo, entendemos o texto como "um espaço aberto a múltiplas leituras" (CHARTIER, 1990, p. 61), resultado de representações simbólicas, cujos poderes de grupos sociais dominantes materializam-se por meio dele. Tais recortes da realidade materializam um ethos discursivo ${ }^{5}$. Isto ocorre, uma vez que todo universo de sentido no discurso é dado por ele e por um posicionamento discursivo, no qual as ideias inseridas constituem a corporalidade discursiva. Esta, por sua vez, leva o coenunciador a se identificar com a fala e com o ethos dicursivo dado, pois

o universo de sentido que o discurso libera impõe-se tanto pelo Ethos quanto pela "doutrina"; as "ideias" apresentam-se por uma maneira de dizer que remete a uma maneira de ser, à participação imaginária em um vivido. O texto não é para ser contemplado, ele é enunciação voltada para um coenunciador que é necessário mobilizar para fazê-lo aderir "fisicamente" a um certo universo de sentido. O poder de persuasão de um discurso decorre em boa medida do fato de que leva o leitor a se identificar-se com a movimentação de um corpo investido de valores historicamente especificados. (CHARTIER, 1990, p. 61)

A noção de discurso da qual nos valemos é a de Bakhtin. Neste sentido, entendemos que a língua enquanto possibilidade de materialização de discursos, impedenos de desvinculá-la de seus falantes e de seus atos, das esferas sociais e dos valores ideológicos que a norteiam. Com isso, o trabalho vai tratar da materialização de um discurso, o qual se dá através das ações e falas do Super-Homem, pois

o discurso é como o 'cenário' de um certo acontecimento. A compreensão viva do sentido global da palavra deve reproduzir esse acontecimento que é a relação recíproca dos locutores, ela deve 'encenála', se se pode dizer; aquele que decifra o sentido assume o papel de

\footnotetext{
${ }^{4}$ Embora enquanto discursos, as HQ's e a História estejam próximas, elas também apresentam traços distintivos que não podem ser ignorados, visto que "os recursos de abstração dos desenhos são amplos. Podemos contar uma estória, em desenhos, do começo ao fim ou do fim para o começo; ainda, indo e vindo com em um contraponto musical; enfim, jogando todos os "quadrinhos" - todos os momentos da estória - na mais completa desordem. Com paciência e jeito será possível recompor a ordem chamada de natural. Com as palavras não é assim. Se eu puser ao acaso em um livro todas as palavras que ele contém, mas desordenadas de todo, ninguém conseguira "ler" a estória, por mais que o tente" (Cf. GAIARSA, 1977, p. 116-7).

5 Pode-se observar que "o ethos é uma noção discursiva, ele se constrói através do discurso, não é uma "imagem" do locutor exterior a sua fala; o ethos é fundamentalmente um processo interativo de influência sobre o outro; é uma noção fundamentalmente híbrida (sociodiscursiva), um comportamento socialmente avaliado, que não pode ser apreendido fora de uma situação de comunicação precisa, integrada ela mesma numa determinada conjuntura sóciohistórica"(Cf. MAINGUENEAU, 2008, p. 17)
} 


\section{VOZES $_{\text {\&IÁLORO }}^{\mid}$}

Itajaí, v. 18, n. 02, jul/dez 2019

ouvinte; e para sustentá-lo, deve igualmente compreender a posição dos outros participantes. (BAKHTIN, 1981, p. 189)

Por ter como objeto de estudo as Histórias em Quadrinhos do personagem Superman, a constituição e mais especificamente a relação desse discurso com a História e a Memória, a pesquisa que realizamos propõe-se "identificar o modo como em diferentes lugares e momentos, uma determinada realidade social é construída, pensada, dada a ler”. (CHARTIER, 1990, p. 16 - 17)

Dessa forma, a representação da realidade social como uma construção simbólica adverte-nos a indagar: "quem deseja recordar? E por quê? Qual a versão do passado que se registra e se preserva? E o que é que ficou esquecido?” (CATROGA, 2001, p. 59) Ou então: Por que se escolheu esquecer? Quais forças sociais impeliram este esquecimento? Tais considerações chamam a atenção para o fato do documento ser:

um produto da sociedade que o fabricou segundo as relações de forças que aí detinham o poder. Só a análise do documento enquanto monumento permite à memória coletiva recuperá-lo e ao historiador usá-lo cientificamente, isto é, com pleno conhecimento de causa. (LE GOFF, 1990, p. 545)

Esquematicamente, a presente pesquisa tem seu recorte temporal definido a partir de fragmentos das histórias em quadrinhos publicadas entre 1958 e 1981. Dada a impossibilidade de explorar todo o material nos limites deste artigo, selecionamos quatro edições: a publicação de número 541 de 1958; a de número 306 de 1963; e dois crossovers, um do Super-Homem vs. Homem-Aranha (edição especial de 1976) e outro nosso herói vs. Espectro (revista de número 29 de 1981). A justificativa para escolha remete ao fato da memória e a história se entrelaçarem para constituir a narrativa do messias estadunidense. Ademais, a escolha visa uma aproximação com a temática e um primeiro esforço exploratório sobre a relação entre a memória e as hq's do Superman, com jogos e as relações de poder inerentes. Como ressaltou Umberto Eco:

não muito tempo atrás, se quisessem tomar o poder político num país, era suficiente controlar o exército e a polícia [...] Hoje um país pertence a quem controla os meios de comunicação. Se a lição da história não parece convincente, podemos recorrer à ficção, que - como ensinava Aristóteles - é bem mais verossímil que a realidade. (ECO, 1984, p. 165)

Se nos quadrinhos o personagem completou 80 anos em 2018, ultrapassando a marca de 1.000 revistas publicadas pela DC Comics (LIMA, 2018, sp), recentemente virou estrela dos games: Justice League Task Force (1995), Justice League: Injustice For All (2002), Justice League Chronicles (2003), Justice League Heroes (2006), Mortal Kombat Vs. DC. Universe (2008), Justice League Heroes United (2009), DC Universe Online 


\title{
VOZES $_{\text {\&DÁLORO }}^{\mid}$
}

Itajaí, v. 18, n. 02, jul/dez 2019

(2011), Lego Batman vs. Super Heroes (2012) e Injustice Gods Amongus (2013). (CALARI, 2013, p. 108)

Além disso, é objeto central em cinco longas-metragens e contracena em outros três (contracena com Batman e Mulher Maravilha em Batman Vs. Superman: a Origem da Justiça, 2016 e em a Liga da Justiça em 2017). Sobre ele há também séries de TV como: Adventures of Superman (1951 - 1958), The New Adventures of Superman (1993 - 1997), Smallville (2001 - 2011), Supergirl (2015 - atual). Quanto aos desenhos, foram mais de 9: Superman (Fleischer Studios - déc. 40), The New Adventures of Superman e The Superman /Aquaman Hour of Adventure (1966 -1969), Superamigos (1973 - 1983), Superman: The Animated Series (1996 - 2000), Liga da Justiça (2001- 2004), etc.

Antes da TV, ele ganhou o rádio com roteiro de Robert Joffe (Robert Maxwell). Superman era interpretado por Clayton "Bud" Collyer, no programa que estreou às $17 \mathrm{~h} 15$ de 12 de fevereiro de 1940. Muitas frases atribuídas ao herói foram criadas neste programa de rádio. De forma sutil, foram feitas mudanças no enredo criado por Siegel e Shuster, as quais se tornaram permanentes. Por exemplo: “o jornal era o Flash Diário, não Estrela Diária, seu editor era paris White, não George Taylor; uma personagem conhecida apenas como srta. Lane era uma telefonista, não uma repórter, e o Superman chega à terra já adulto e com o traje característico" (WELDON, 2016, p. 55).

\section{História em imagens: o que nos dizem as HQ's}

Moacy Cirne afirma que há códigos morais que regem as editoras especializadas na produção e distribuição de histórias em quadrinhos tanto no Brasil quanto internacionalmente. Até 1970, o código brasileiro salientava que:

\begin{abstract}
- as histórias em quadrinhos devem ser um instrumento de educação, formação moral, propaganda dos bons sentimentos e exaltação das virtudes sociais e individuais; - é necessário o maior cuidado para evitar que as histórias em quadrinhos, descumprindo sua missão, influenciem perniciosamente a juventude de deem motivo a exageros da imaginação da infância e juventude; - não é permitido o ataque ou a falta de respeito a qualquer religião ou raça; - os princípios democráticos e as autoridades constituídas devem ser prestigiados, jamais sendo apresentados de maneira simpática ou lisonjeira os tiranos e inimigos do regime e da liberdade. (CIRNE, 1974, p. 11)
\end{abstract}

Para Ariel Dorfman e Manuel Jofrée, as histórias em quadrinhos tradicionais, travestidas de entretenimento, impediam o homem de refletir sobre si mesmo: os autores as acusam de agir como mecanismo de defesa da ordem burguesa, ocupando os momentos

\footnotetext{
${ }^{6}$ Antes destes estudiosos, o psiquiatra alemão Fredric Wertham em seu livro Seduction of the Innocent publicado em 1954, já alertava os leitores sobre o teor ideologizante das histórias em quadrinhos. Ele defendia a tese de que as revistas em quadrinhos eram uma forma ruim de literatura popular e um sério fator da delinquência juvenil.
} 


\title{
VOZES $_{\text {\&IÁLORO }}^{\mid}$
}

Itajaí, v. 18, n. 02, jul/dez 2019

de ócio - nos quais o homem tem tempo para pensar sobre a realidade - com diversão rápida e redundante. Afirmam os autores que os

\begin{abstract}
quadrinhos são uma arma. Os meios de comunicação são uma arma. Mas o uso que fazemos dela não é pra matar, mas para defender. Porque nossas armas são outras. A verdade, a liberdade, a realização humana, o tudo em todos, a unidade dos seres humanos. No socialismo não existirão armas. No socialismo não haverá homicídios. No socialismo não existirão homens que matem outros homens, nem com trabalho nem com nenhuma arma. Porque não haverá balas nem armas, não haverá quadrinhos nem capital. Não haverá falsas riquezas. (DORFMAN; JOFRÉ 1978, p. 93)
\end{abstract}

A leitura de um texto/documento seja ela qual for, é uma prática histórica e "cada prática histórica não estabelece seu lugar senão graças ao aparelho que é ao mesmo tempo a condição, o meio e o resultado de um deslocamento" (CERTEAU, 1982, p. 83). Então, “ os documentos não falam, senão quando sabemos interrogá-los” (BLOCH, 2002, p. 08). Neste sentido, considerando as histórias em quadrinhos como documentos históricos e, consequentemente, como textos que expressam uma compreensão de mundo. Assim, as histórias em quadrinhos possibilitam ler uma cultura, são imagens e, portanto, documentos que representam uma dada realidade e seus constitutivos. Todavia, elas só ganham sentido aos olhos do observador, do público, do outro, pois

\begin{abstract}
é a interação social que produz sentidos, mobilizando diferencialmente (no tempo, no espaço, nos lugares e circunstâncias sociais, nos agentes que intervêm) determinados atributos para dar existência social (sensorial) a sentidos e valores e fazê-los atuar. [...] É necessário tomar a imagem como um enunciado, que só se apreende na fala, em situação. (MENEZES, 2013, p. 28)
\end{abstract}

As histórias em quadrinhos como enunciado/palavra, numa perspectiva bakhtiniana, comportam pelo menos duas faces, visto que toda palavra "é determinada tanto pelo fato de que procede de alguém como pelo fato de que se dirige a alguém. Ela constitui justamente o produto da interação do locutor e do ouvinte. Toda a palavra servese de expressão a um, em relação ao outro. Através da palavra, defino-me, em relação ao outro”. (BAKHTIN, 2006, p. 115)

Logo quando se enuncia, enuncia-se para alguém, não há aleatoriedade, há intenções comunicativas, há ditos, representações e projeções de um $E u$ que marca discursivamente sua diferença em relação a esse Outro e exige-se dele uma resposta ao dado. Vale ressaltar que a presente pesquisa trabalhará apenas com o polo produtor de bens culturais, no caso específico, o estadunidense e alguns poucos fragmentos dos produtos, a saber algumas hq's do Superman. Para ilustrar a alteridade discursiva, observemos a capa abaixo, publicada em plena Segunda Guerra: 


\section{VOZES $_{\text {\&DÁLORO }}^{\mid}$}

Itajaí, v. 18, n. 02, jul/dez 2019

Figura 1 - Propaganda da Segunda Guerra Mundial nas hq's de Superman

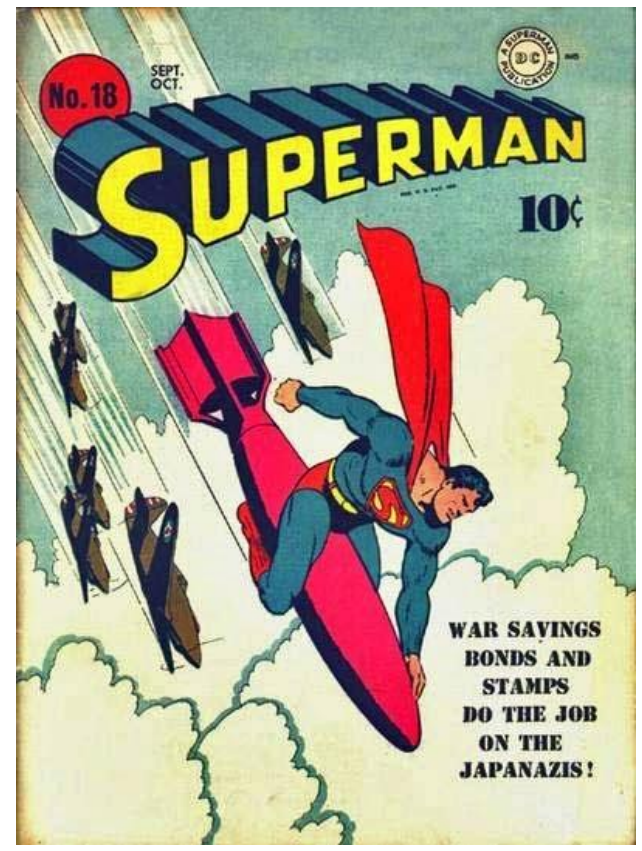

Fonte: WILLIAMS, Blake. Wars Bond, 2014. Disponível em: <https://bit.ly/2zoDfOR>. 7

O herói americano aparece na ponta de uma corrida, atrás dele estão os japonazis ${ }^{8}$, numa alusão de que os países do Eixo estariam em desvantagem e até mesmo perdendo o conflito mundial. Como produto cultural estadunidense, nosso objeto de estudo criou a representação de um país que era invencível, forte, resiliente, astuto e moralmente irrefutável. É evidente que as histórias em quadrinhos promoviam uma visão positiva do governo, transmitiam informações militares do conflito e, durante a Segunda Guerra, veiculavam “anúncios” solicitando para "as pessoas comprar títulos de guerra, envolver-se com a sucata e participar de outros eventos relacionados à guerra”. (SCOTT, 2011, p. 07)

Deve-se observar que o governo americano se esforçava para que o combate militar ao inimigo ocorresse também de forma simbólica. Para isso, valia-se de várias estratégias, mas a principal se dava através do OWI (Office of War Information) ${ }^{9}$, pois o órgão "queria dar às pessoas, em geral, detalhes precisos da guerra (a censura do governo estava

\footnotetext{
${ }^{7}$ Acesso: dez-2018. [Tradução nossa: selos e poupanças de guerra fazem o trabalho sobre o japanazis!]

${ }^{8}$ Nos EUA é um termo informal e de caráter depreciativo constituído pela junção de duas palavras: japoneses e nazistas. Segundo o site: <https://bit.ly/321ZYfo>. Acesso: dez-2018, corresponde a "qualquer cidadão das potências do Eixo que se opusesse aos Aliados na Segunda Guerra Mundial".

${ }^{9}$ O Escritório de Informações de Guerra dos Estados Unidos foi uma agência do governo dos Estados Unidos criada durante a Segunda Guerra Mundial. OWI operou a partir de junho de 1942 até setembro de 1945. Através de transmissões de rádio, jornais, cartazes, fotografias, filmes e outras formas de mídia, o OWI era a conexão entre a frente de batalha e as comunidades civis. Disponível em: <https://bit.ly/327TQIN>. Acesso: dez-2018.
} 


\section{VOZES $_{\text {\&IÁLORO }}^{\mid}$}

Itajaí, v. 18, n. 02, jul/dez 2019

tecnicamente limitada à informação militar).” (SCOTT, 2011, p. 52). Concomitante a isto, o OWI evitava a publicação de imagens que pudessem desencorajar ou desmoralizar o público. Por essa razão, os desenhos e filmes infantis e adultos tinham um tom otimista e patriótico. A adesão desejada pelo órgão de informação americano criou estratégias diversas para cooptar o público, os quadrinhos "também promoveram coleta de papel e metal, bem como selos de guerra (denominados em centavos poderiam ser comprados incrementalmente e eventualmente convertidos em títulos de guerra), para promover o sentido de que "estamos todos juntos nisso". (SCOTT, 2011, p. 07)

Ainda conforme Scott, alguns personagens conclamavam os leitores a estarem vigilantes, pois os inimigos esperavam o melhor momento para o ataque, com um centavo, por exemplo, o público atuando como Sentinela poderia ajudar Cap ${ }^{10}$ e Bucky a salvar os americanos. Algumas histórias, segundo Scott, afirmavam que se podia confiar nas declarações oficiais do governo dos Estados Unidos e das Nações Unidas, outras instruiam sobre como diferenciar as aeronaves aliadas das do Eixo, havia ainda algumas que possibilitavam às crianças que enviassem uma versão infantil de uma mira de bombardeio para anexar a um modelo de avião a ser publicado posterirmente.

\section{Superman: gênese e messianidade}

Eric Hobsbawn dissecou a chamada Era da Guerra Total. Afirmou que a Primeira Guerra foi um episódio de extrema carnificina que, além não resolver as tensões existentes, ainda criou as bases para o surgimento de uma ultradireita e posteriormente de uma Segunda Guerra Mundial. Para ele, "a Segunda Guerra Mundial ampliou a guerra maciça em guerra total” (HOBSBAWN, 1995, p. 50). Ele ratifica esta afirmação, alegando que

o monstro da guerra total do século XX não nasceu já do seu tamanho. Contudo, de 1914 em diante, as guerras foram inquestionavelmente guerras de massa. Mesmo na Primeira Guerra Mundial, a Grã-Bretanha mobilizou 12,5\% de seus homens para as Forças Armadas, a Alemanha $15,4 \%$, e a França quase $17 \%$. Na Segunda Guerra Mundial, a porcentagem de força humana total que foi para as Forças Armadas esteve muito geralmente nas vizinhanças de 20\%. (MILWARD apud HOBSBAWN, 1995, p. 51)

No período entre guerras, mais especificamente entre 1918 e 1928, a produção norte-americana conheceu grande prosperidade caracterizando o chamado American Way of Life, resultando em geração de empregos, queda de preços, aumento de produção da agricultura, consumo intensivo, expansão de crédito e parcelamento de pagamentos.

10 Referência ao Capitão América, o qual tinha como parceiro James Buchanan "Bucky" Barnes, também conhecido como Soldado Invernal, um super-herói mascarado fictício dos quadrinhos da Marvel Comics. Foi criado por Joe Simon e Jack Kirby e era o jovem parceiro do Capitão América. Disponível em: <https://bit.ly/2ZzbK3j>. Acesso: dez-2018. 


\section{VOZES $_{\text {\&IÁLORO }}^{\mid}$}

Itajaí, v. 18, n. 02, jul/dez 2019

Todavia, em 1929 ocorreu a quebra da bolsa de valores de Nova York, fato que deu início a Grande Depressão, a qual se findaria em 1933, devido aos efeitos do New Deal de Franklin Roosevelt, articulado por Maynard Keynes, ao lado de vários programas de ajuda social.

Para os americanos, a depressão de 1929 ficou gravada na alma por seu forte e contínuo desemprego. "Se a intensidade da queda nos preços e da contração monetária não era inteiramente inédita, a intensidade e a duração do desemprego era nova e chocante” (ROTHBARD, 2012,p. 32). Até aquele momento, a proporção de desempregados nunca atingira o nível daquele período, "a proporção da força de trabalho americana que ficava desempregada raramente atingia os $10 \%$ nos piores pontos das depressões anteriores, mas passou de 20\% em 1931, e ficou acima de $15 \%$ até o começo da Segunda Guerra Mundial” (ROTHBARD, 2012, p 32). Nove anos depois da quebra da bolsa de valores nos EUA, em 18 de junho de 1938, o público conheceria o Superman, o Homem de Aço. ${ }^{11}$

Na primeira edição de ActionComic, um homem com roupa de fortão de circo erguia um carro com a força de seus braços enquanto a ex-vítima o olhava assustada e outro homem corria desesperado com as mãos na cabeça, como se não acreditasse no que via. Quem seria aquele homem? De onde viera? Como poderia um ser humano erguer um carro com a força do próprio corpo apenas?

Segundo Cirne, O Homem de Aço é um herói da classe média americana que está "em busca de autoafirmação, identificando-se com a prepotência imperialista [...] e a possibilidade neurastênica de usufruir de uma dupla identidade" (CIRNE, 1982, 38).

Numa época de aumento do desemprego em decorrência Grande Depressão, em que o "fascismo, corrupção empresarial e crime organizado aumentaram tanto que, no final da década de 1930, pareciam problemas insuperáveis e insolúveis. O Super-homem saiu das fileiras do homem comum para combater essas ameaças” (KNOWLES, 2008, p. 139). Conforme o estudioso Cirne,

antes da 2. a grande guerra, mas já em pleno nazismo, houve a necessidade do lançamento de super-heróis, cujos poderes, em sendo extraordinários, desafiassem a lógica humana. Engendrado pelas profundas contradições da sociedade americana, o super-herói, em sua forma ideológica mais radical, [...] é um produto nazistificante que, ao surgir, volta-se contra o nazismo por um imperativo político, assim como mais tarde se voltará contra o socialismo [...] por um imperativo de ordem ideológica. (CIRNE, 1982, 38).

\footnotetext{
${ }^{11}$ Cf. ROBB, Brian J. A identidade secreta dos super-heróis: a história e as origens dos maiores sucessos das HQ's: do super-homem aos vingadores. Rio de Janeiro: Valentina, 2017. p. 13. "A maioria dos gibis se encontrava à venda nas bancas até dois meses antes da data declarada na capa. Datas de publicação nas capas são usadas o tempo todo, e o verdadeiro mês só é destacado quando se torna relevante".
} 


\section{VOZES $_{\text {\&IÁLORO }}^{\mid}$}

Itajaí, v. 18, n. 02, jul/dez 2019

Talvez, possa-se dizer que o super-herói americano surge da fraqueza da sociedade americana. "A Depressão havia atingido duramente as famílias deles. Então em lugar do homem rico e urbano, o alter ego que Siegel e Shuster tinham em mente era o trabalhador honesto, um repórter”. (WELDON, 2016, p. 28.)

Figura 2 - Logotipo do Superman apresentado em 1938 na ActionComics $n^{\circ} 1$

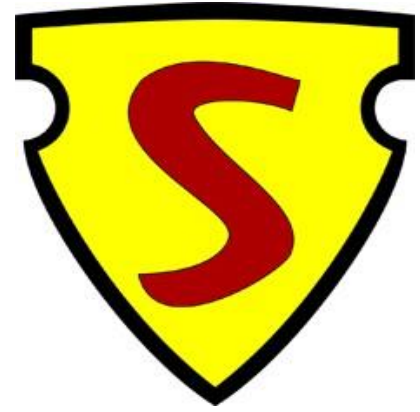

Fonte: MALTEZ, Joana. O símbolo do Superman ao longo dos tempos, 201812

O super-herói americano ensejava ser a esperança ${ }^{13}$ num momento histórico específico. Um salvador da pátria, um messias, alguém se sacrificasse em nome do altruísmo para salvar os outros. Institui-se, assim, um dos aspectos que mais solidificarão a fama do personagem: o "super-herói messiânico torna-se muito popular porque lida com ansiedades profundamente arraigadas na vida americana” (KNOWLES , 2008, p. 139). Segundo Hughes-Hallett:

Heróis são pessoas dinâmicas e sedutoras - de outra forma não seriam heróis - e a fúria heroica é emocionante de se contemplar. É a expressão de um espírito soberbo. Associa-se à coragem, à integridade e ao desdém pelas mesquinhas concessões que permitem à maioria não-heroica ir levando a vida - atributos esses amplamente considerados nobres. A fúria heroica tem também, e em consequência disso, um enorme potencial para desestabilizar a ordem estabelecida. O Aquiles de Homero era "o melhor dos aqueus", o maior entre os guerreiros gregos, mas sua fúria não era dirigida contra os inimigos de seu povo, e sim contra Agamenon, líder de seu povo. A Ilíada é uma celebração do encanto letal de Aquiles: é também a história do quão próximo ele esteve de levar à derrota a comunidade da qual ele era o mais brilhante representante. (HUGHES-HALLETT, 2007, 13)

\footnotetext{
12 Disponível em: <https://bit.ly/2MHWrPG >. Acesso: set-2018.

13 No trailer do filme lançado em 2013, Man of Steel, aos 2min, 38 seg. há uma conversa entre Lois Lane o super-herói, nela a moça indaga-o quanto ao significado da letra S estampada na roupa dele, ele acaba por dizer que no mundo ao qual pertence (Krypton), a letra corresponde a esperança. “Superman: In my world it's not an S, it's mean “Hope”./ Lois Lane: Well, here it's an S. How about Super?/ Superman: Excuse me? [Tradução nossa: "Superman: No meu mundo não é um S, significa "Esperança" / Lois Lane: Bem, aqui é um S ... Que tal Super...? / (um barulho estranho acontece e corta a conversa) / Superman: Com licença?"]. In: CURIOSO, Ultra. Qual é o Significado da letra "s" no uniforme do Superman? Disponível em: <https://bit.ly/2HritUj>. Acesso: dez-2018.
} 


\section{VOZES $_{\text {\&IÁLORO }}^{\mid}$}

Itajaí, v. 18, n. 02, jul/dez 2019

O personagem octogenário foi criado pelos judeus Jerry Siegel e Joe Shuster. Siegel foi o primeiro roteirista da franquia, enquanto Shuster foi seu primeiro artista. Juntos foram responsáveis por transformar a DC Comics numa das maiores empresas de quadrinhos do mundo. "Siegel nasceu em Cleveland, Ohio, filho de um pintor de sinais que imigrou da Rússia. Shuster viu a luz em Toronto, Canadá, como filho de um alfaiate e tinha raízes holandesas-ucranianas". ${ }^{14}$ Segundo Weldon (2016), eles se conheceram em Cleveland em 1931 quando o pai de Shuster mandou o filho para a Glenville High School.

Antes da criação de Superman e outros personagens (Famoso Soldado da Fortuna $^{15}$, Dr. Oculto, o Detetive Fantasma ${ }^{16}$, Homens Federais ${ }^{17}$, etc), Siegel e Shuster tentaram, sem sucesso, ganhar a vida publicando romances de ficção científica. Então, fundaram sua própria revista, a Science Fiction, em outubro de 1932, a qual em sua terceira edição, de janeiro de 1933, propiciou a primeira aparição do Superman em O Reinado de Superman $^{18}$, contudo, não da forma como o conhecemos hoje.

Nela aparece o personagem que se torna um vilão, após ser criado por um cientista semelhante a Lex Luthor.

O professor Ernest Smaley tira um "vagabundo faminto" de uma fila para comprar pão e injeta nele um elemento que isolou de um meteoro. $\mathrm{O}$ sujeito da experiência (chamado o tempo todo de "super-homem") ganha imediatamente o poder de percepção extrassensorial, mata seu criador e começa a escravizar outras pessoas com a mente. Seu plano: era pensamentos de ódio que fariam a humanidade se voltar contra ela mesma. (WELDON, 2016, p. 22)

A história foi recusada por várias editoras. Mas, em agosto do mesmo ano, os quadrinistas Siegel e Shuster fizeram uma nova tentativa com The Superman ${ }^{19}$. Nela "toda a história do Superman é contada em apenas uma página, sendo os três primeiros quadros reservados para narra e ilustrar brevemente: 1) a destruição de Krypton; 2) a migração do foguete; 3) a infância do herói” (CALLARI, 2013, p. 109). Na página seguinte, para impedir que um cidadão seja condenado à morte por eletrocussão, o herói invade o apartamento de um lobista, agride-o e cai do prédio em que mora o político, com ele nos braços, por calcular errado seu pulo.

\footnotetext{
${ }^{14}$ KNUDDE, Kjell; SCHUDDEBOOM, Bas. Jerry Siegel e Joe Shuster. Disponível em: $<$ https://bit.ly/2KupO2C >. Acesso: set-2018.

${ }^{15}$ História de espadachim publicada em New Fun na edição de número 6 de outubro de 1935.

${ }_{16}$ História sobre um médico que lutou contra um vampiro, publicada também em 1935.

${ }^{17}$ História sobre o agente do governo Steve Carson e suas aventuras de ação, publicada em janeiro de 1936.

${ }^{18}$ SIEGEL, Jerry; SHUSTER, Joe. Ficção Científica: A Vanguarda da Civilização Futura, vol. 1 No. 3. Jan. 1933. Obra completa disponível em: <https://bit.ly/3420Tyh>. Acesso em 20 de setembro de 2018.

${ }^{19}$ BEST, Daniel. 1933's 'The Reign of The Superman' - The First Superman Story, Ever, 2012.

Disponivel em: <https://bit.ly/2ZuMIm6>. Acesso: nov-2018.
} 


\title{
VOZES $_{\text {\&IÁLORO }}^{\mid}$
}

Itajaí, v. 18, n. 02, jul/dez 2019

Conforme Joanne Siegel novamente, os autores receberam a negativa da publicação, fato que só se alterou em 1938, quando a historieta chegou às mãos do editor da DC Comics, Harry Donenfeld, por intermédio de MC Gaines (chefe de Mayer) e Sheldon Mayer (um editor do sindicato McClure). Então, em 1938, os amigos judeus efetivaram o personagem americano ${ }^{20}$.

Segundo Weldon, "Siegel era um garoto tímido, um solitário de óculos que não praticava esportes e suspirava pelo tipo de garota que desprezava rapazes como ele" e "Shuster, amigo de Siegel, era um garoto baixinho e míope cuja principal válvula de escape, além da própria devoção àquelas práticas de levantamento de peso que Siegel adorava ridicularizar, era desenhar quadrinhos" (WELDON, 2016, p. 20). Tais fatos sugerem que "ambos com 17 anos, desajeitados e impopulares no ensino médio, inventaram o manso Clark Kent e seu poderoso alter ego, Super-Homem, para atrair garotas e superar suas humildes origens em Cleveland”. (COLTON, 2008, p. sp)

Siegel afirmou sobre o surgimento do personagem: "enquanto todos os pensamentos surgiam na minha cabeça, apareceu o conceito de que... o Superman poderia ter dupla identidade, e que em uma delas ele seria manso e moderado, como eu era, e usaria óculos, como eu” (WELDON, 2016, p. 26). Se, no mundo real, a origem do personagem está associada a características físicas e fatos ocorridos com seus criadores, na ficção foi no mítico planeta de Krypton que ele surgiu. Knowles afirmou que o

\begin{abstract}
Super-Homem é Kal-El, o último filho de Krypton, enviado ao espaço quando bebê por seu pai, um cientista, pouco antes de seu planeta explodir. Sua cápsula espacial aterrissa na cidade de Smallville, situada no Meio-Oeste americano. Ele é encontrado por um casal de idosos, os Kent, que dão ao bebê o nome de Clark e o criam como se fosse seu próprio filho. Clark, que desde o início demonstra sua força prodigiosa, sai de Smallville e vai pra Metrópolis, onde trabalha como repórter para o Planeta Diário. Em momentos de crise, ele veste seu uniforme azul e vermelho e usa seus poderes - voô, superforça e visão de raio x - para lutar pela verdade e pela justiça. (KNOWLES, 2008, p. 141 - 142).
\end{abstract}

Segundo Jones, "Jerry e Joe receberam um cheque no valor de 130 dólares. E assinaram um papel cedendo todos os direitos sobre o Super-Homem para a editora. ” (JONES, 2006, p. 234). Contudo, conforme David Colton (2008), em contrapartida a DC Comics adquiriu os direitos do personagem indefinidamente. Dada a vultosa aceitação por parte do público, por diversas vezes, durante 37 anos, os progenitores do Super-homem tentaram reaver os direitos sobre a obra, assim como sobre sua publicação, obtendo pouco êxito, já que os direitos sobre o personagem nunca lhes foram cedidos.

Ainda conforme Colton, este panorama foi alterado quando em 1975, com a Warner Bros pagando US $\$ 3$ milhões pelos direitos de fazer Superman The Movie. Nesta

${ }^{20}$ SIEGEL, Joanne; Siegel Laura. TM @ DC Comics, 1938. Apud SCHUMER, Arlen. The Original Superman, 1998. Disponível em:<https://bit.ly/2Zvedrx>. Acesso: nov-2018. 


\section{VOZES $_{\text {\&IÁLORO }}^{\mid}$}

Itajaí, v. 18, n. 02, jul/dez 2019

última tentativa de ressarcimento sobre a propriedade intelectual de ambos, eles foram auxiliados pela comunidade artística e por fãs que conheciam seu trabalho, incluindo Jerry Robinson. ${ }^{21}$ Dessa vez, a DC Comics concordou em pagar aos dois US \$ 20 mil por ano pelo resto da vida e ainda adicionar a inscrição "Superman criado por Jerry Siegel e Joe Shuster" em todos os materiais impressos e filmados dali em diante.

Além de Clark Kent, outros personagens compõem o enredo. Entretanto, a personagem que mais contracenou com o herói foi Lois Lane, presente nos quadrinhos desde 1938 na edição número $1^{22}$.

Outro personagem essencial na trama é Alexander Joseph Luthor. Arqui-inimigo do Superman, apareceu pela primeira vez na edição $23^{23}$ da ActionComics em abril de 1940, quando Lois Lane e Clark Kent entrevistam-no juntamente com o professor Ogilvy, depois de descobrirem seu plano diabólico para provocar uma guerra entre duas nações europeias. Concomitante a este fato ficcional, acontecia a Segunda Guerra Mundial. Em sua primeira exibição, ele não tem poder algum. (MANNING, 2017).

Lex Luthor foi eleito o presidente dos EUA em 2000 nos quadrinhos do Superman. Antes disso, foi um dos primeiros personagens das bandas desenhadas a utilizar a bomba atômica (1944). Contudo, o Departamento de Defesa dos Estados Unidos - à época denominado Departamento de Guerra dos Estados Unidos - impediu a publicação deste acontecimento no enredo das hq's do herói até 1946. Fato bastante interessante quando se examina a duração da Segunda Guerra Mundial (1939 a 1945).

Anos antes, em agosto de 1942, a DcComics publicou a capa ${ }^{24}$, na qual a Alemanha (Hitler) e Japão (Hirohito) mostram-se apavorados com o poderio bélico dos EUA, representado na capa pela postura corporal e olhar do herói americano. No conflito mundial, havia a oposição de dois lados antagônicos chamados de Eixo (Alemanha, Itália e Japão como principais nações) e Aliados (liderados por Estados Unidos, União Soviética, Reino Unido e a França).

\section{Superman: em a luta contra o esquecimento}

Além dos exemplos acima que remetem a momentos da história mundial, o personagem Superman está relaciona à memória por muitas razões, uma delas é fato de ele poder falar praticamente todas as línguas da Terra, devido as suas peregrinações e

\footnotetext{
${ }^{21}$ Cocriador do Robin, o parceiro do Batman (juntamente com Bob Kane e Bill Finger), do Coringa e do Joker (com Bill Finger). Falecido em 2011. Fonte: <https://bit.ly/2MGI2TX>. Acesso: nov-2018.

22 SIEGEL, Jerry; SHUSTER, Joe, 1938. Disponível em: <https://bit.ly/2Nx9KSV>. Acesso: nov-2018.

${ }^{23}$ SIEGEL, Jerry; SHUSTER, Joe, 1940. Disponível em: <https://bit.ly/2U7ofhq>. Acesso em 01 de outubro de 2018. [Tradução nossa: Dentro do esconderijo de Luthor... Este repórter sabe demais Ele dever ser eliminado. Como você quiser, Oh poderoso Luthor!] ${ }^{24}$ BROTHERS, Bunk. Golden Age Superman, 1942. Disponível em: <https://bit.ly/344z8Fe>. Acesso: dez-2018.
} 


\section{VOZES \\ ¿DIÁlOGO}

Itajaí, v. 18, n. 02, jul/dez 2019

missões de salvamento através do mundo, sem nunca ter estudado tais idiomas. Ao longo dos 80 anos de existência do herói americano, há vários momentos nos quais há um entrelaçamento entre memória e história no enredo do personagem. Por isso analisaremos trechos das histórias em quadrinhos de 1958 a 1981.

O tema da memória aparece claramente na narrativa de Superman quando são apresentados os cristais, os quais ele utilizava para armazenar dados sobre seus pais e sua história. A Fortaleza da Solidão ${ }^{25}$ apareceu pela primeira vez na história do personagem na capa da edição de 1958 que segue adiante. "O Super-Homem às vezes sente necessidade de se retirar com suas lembranças e voa através de montanhas inacessíveis para onde, no coração da rocha, defendida por uma enorme porta de aço, fica a Fortaleza da Solidão" (ECO, 1984, p. 10).

Figura 3 - A primeira aparição do "Forte Superman"

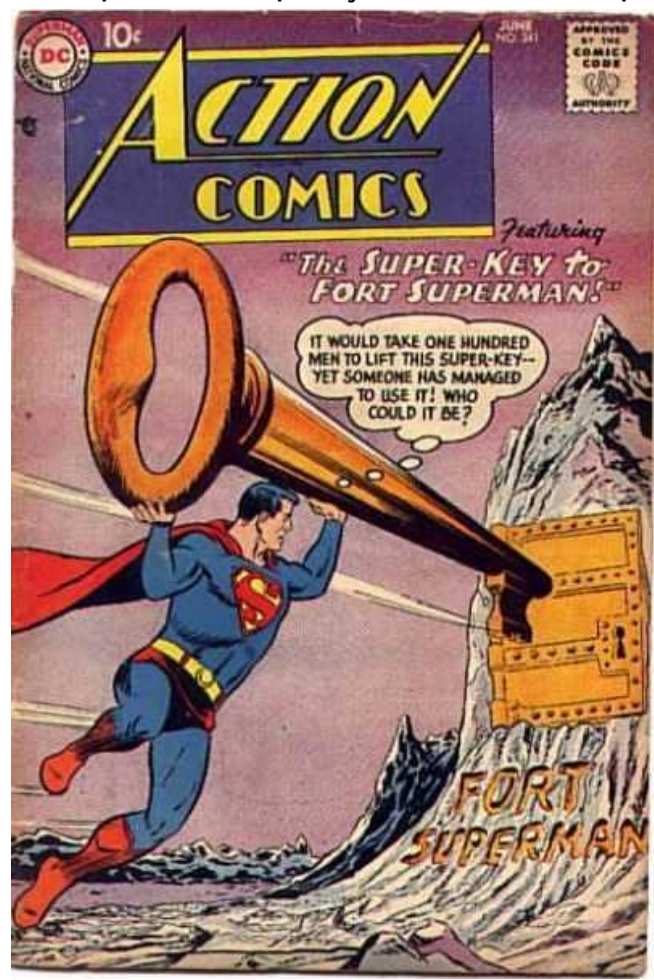

Fonte: The Super Key to Fort Superman, número 241, junho de 1958. 26

A Fortaleza da Solidão é um mecanismo identitário, uma estratégia de acesso ao passado no enredo no personagem, funcionava como seu "porto seguro". Lá, além de

\footnotetext{
${ }^{25}$ No filme de 1978, intitulado "Superman", o ator já falecido, Christopher Reeve permanece por um tempo dentro da Fortaleza da Solidão, este ambiente bastante comum na história do herói americano aparece em outras mídias do personagem, como nos episódios 15 e 19 da série Supergirl, ou o episódio 2 "Para Um Homem Que Já Tem Tudo", de A Liga da Justiça, ou ainda no episódio $8 \mathrm{da} 7^{\mathrm{a}}$ temporada da série: Superman: The Animated Series. $\backslash$

${ }^{26}$ Disponível em <https://bit.ly/2ztROew>. Acesso em 09 de novembro de 2018. [Tradução nossa: Seriam necessários 100 homens para levantar esta super-chave... mas ainda assim alguém conseguiu usá-la! Quem poderia ser?]
} 


\title{
VOZES $_{\text {\&DÁLORO }}^{\mid}$
}

Itajaí, v. 18, n. 02, jul/dez 2019

relaxar, Superman realizava experimentos, reativava as lembranças de amigos, mantinha contato com seu pai Jo-El e podia rever seus troféus.

\begin{abstract}
Ali o Super-Homem mantém seus robôs, cópias fidelíssimas de si próprio, milagres da tecnologia eletrônica, que de vez em quando envia pelo mundo para realizar um justo desejo de ubiquidade. [...] O SuperHomem usa fortaleza também como museu de recordações: tudo o que aconteceu em sua vida cheia de aventuras está ali registrado em cópias perfeitas ou até conservado como achado original miniaturizado[...]. (ECO, 1984, p. 10)
\end{abstract}

O segundo episódio mnemônico ocorre na ActionComics número 306 de 1963, quando Clark Kent beija ${ }^{27}$ Louis Lane fazendo-a esquecer da identidade secreta do rapaz. Para isso, ele suga o oxigênio dos pulmões dela, fazendo-a perder também uma parte especifica da sua memória, justamente aquela em que a Supermoça descobre quem era de fato o seu namorado. A atitude de Clark remete ao fato de memória corresponder a poder, “a memória coletiva é não somente uma conquista, é também um instrumento e um objeto de poder” (LE GOFF, 1990, p. 470).

Figura 4 - O Beijo do Esquecimento

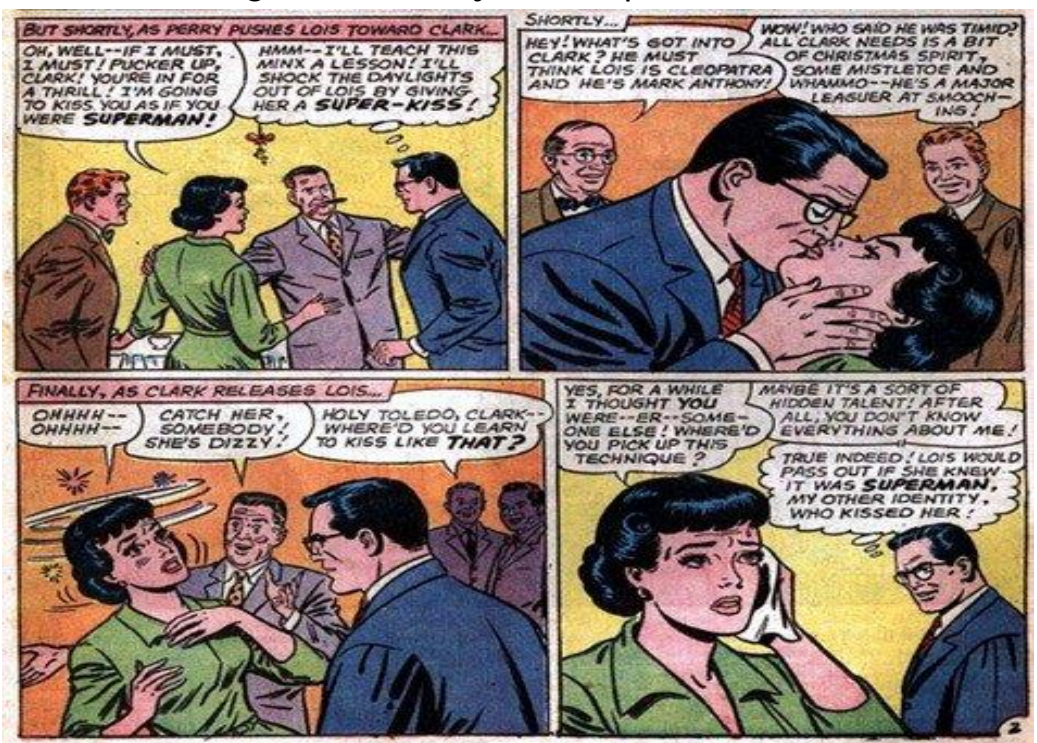

Fonte: Synopsis for Superman: 'The Great Superman Impersonation!", novembro/1963,

p. 0228

\footnotetext{
${ }^{27}$ No filme de 1980, cujo nome é Superman II - A Aventura Continua, esta mesma tática também fora utilizada pelo moço para despistar a suspeita de seu grande amor. Disponível em:< https://bit.ly/2ZsOq7f>. Acesso: nov-2018.

${ }^{28}$ Disponível em: <https://bit.ly/2PkJQnK>. Acesso: nov-2018. [Tradução nossa: (QUADRO 1): Vá pra cima, Clark! Você está com emoção! Eu vou te beijar como se fosse o SUPER-HOMEM! / Hum -Eu vou ensinar a esta sirigaita uma lição! Chocar as luzes do dia de Louis dando-Ihe um SUPER BEIJO! (QUADRO 2): Em instantes... / Ei! O que tem o Clark? Ele deve pensar que Lois é Cleópatra e ele o Marco Antônio! Uau! Ela disse que ele era tímido! Tudo o que Clark precisa é de um pouco de espírito de Natal, um pouco de visco e alguém - Ele é um grande jogador de beisebol em beijar! / (QUADRO 3): Finalmente, quando Clark larga Lois... / Ohhhh -- ohhhh -- / Segure-a, alguém, ela está tonta! / Santo Toledo, Clark -- onde você aprendeu a beijar assim? / (QUADRO 4): Sim, por um tempo eu pensei que você fosse -- outra pessoa! Onde você arranjou esta essa
} 


\section{VOZES $_{\text {\&DÁLORO }}^{\mid}$}

Itajaí, v. 18, n. 02, jul/dez 2019

O poder é semeador de memórias e esquecimentos. Clark ao interferir no acesso das memórias de Lane a seu respeito, permite-nos falar em caráter identitário e alteritário. Analogamente, pode-se pensar nos constructos de memórias que nos permitem acessar a história humana, seus acontecimentos e mártires. Le Goff (1990, p. 469) define a memória como "elemento essencial do que se costuma chamar identidade, individual ou coletiva, cuja busca é uma das atividades fundamentais dos indivíduos e das sociedades de hoje, na febre e na angústia”.

Por tais razões, ela pode se transformar em fonte histórica: primeiro, porque é um rastro humano, o qual o historiador pode acessar; segundo, porque ela erige-se na apreensão tridimensional do tempo (passado, presente, futuro); por fim, porque é resultante do confronto entre os campos mnésicos coletivos e individuais.

O terceiro trecho de análise é aquele no qual que ele se encontra com o HomemAranha. Consegue montar um computador peça por peça depois que este explodiu, baseando-se somente no que lembrava. Na narrativa, essa memória recebe o nome de Memória Eidética; no cotidiano ela recebe o nome de memória fotográfica. Através dessa memória, ele pode armazenar e processar vastas quantidades de informação em sua mente kryptoniana. Mas este superpoder só é possível por que ele possui um outro poder chamado de Visão Raio-X. Assim, Superman vale-se da metamemória para arrancar um elogio do Homem-Aranha. Utilizá-la faz dele um ser ímpar, único e acima da média. A capacidade mnemônica constitui elemento distintivo. Não parece acaso que em seu nome foi acrescido o prefixo super.

\section{Figura 5 - Memória Eidética do Superman}
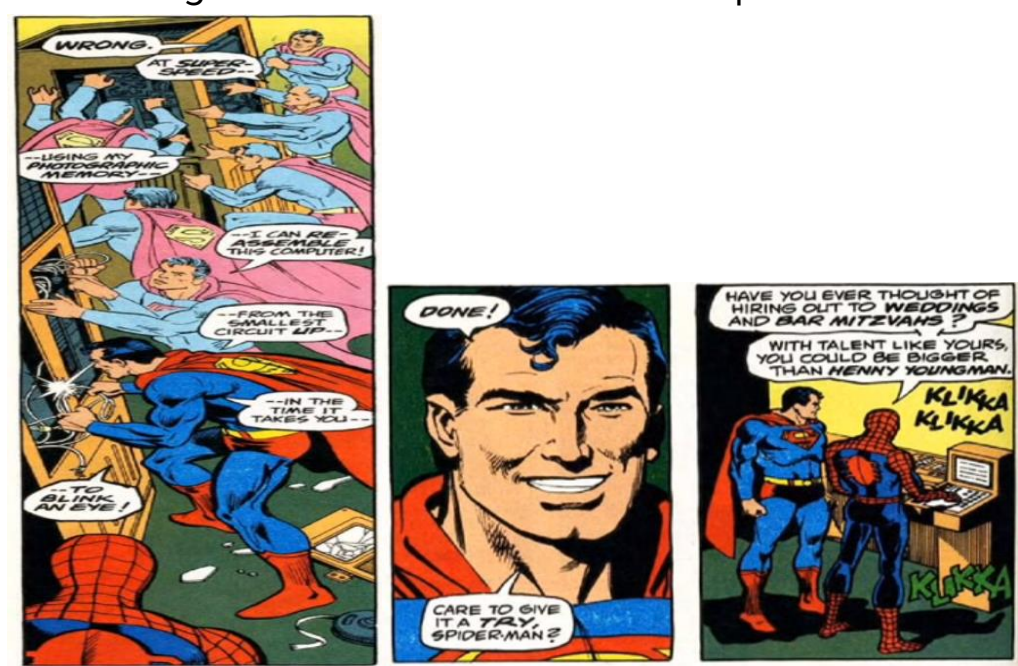

Fonte: Superman vs. The Amazing Spider-Man: The Battle of the Century, 1976, p.6629

técnica? / Talvez seja um talento escondido! Depois você não saberá nada sobre mim! / Na verdade! Lois desmaiaria se soubesse que era o SUPER-HOMEM, minha outra identidade, que a beijou!]

29 Disponível em:< https://bit.ly/2HvTMED>. Acesso: nov-2018. [Tradução nossa: (QUADRO 1) Errado / Em supervelocidade.. / Usando minha memória fotográfica.. / Eu posso remontar este computador! / Desde o menor circuito até / No tempo equivalente / a um piscar de olhos. 


\section{VOZES $_{\text {\&IÁLORO }}^{\mid}$}

Itajaí, v. 18, n. 02, jul/dez 2019

Nesta esteira, é indispensável saber o que é metamemória. Afinal, o que isso significa? A categorização dos níveis da memória proposta por Catroga, demonstra que queiramos ou não, a memória é constitutiva da identidade. Segundo ele, há a metamemória, a qual está relacionada às representações que o indivíduo faz do que viveu, expressa-se como uma capacidade de pensar na própria memória. Além desta, há a protomemória, que concerne aos saberes experiências de socialização e ao nosso habitus, além disso funciona como lembrete de como agir na esfera social, colocando nossas ações no campo do automatismo. Por fim, há o terceiro nível que é a memória propriamente dita e se refere à recordação e ao reconhecimento.

Por fim, o último excerto de análise é um crossover $^{30}$ do nosso herói contra Espectro, no qual Superman e Supergirl destroem o planeta Warworld. Sua prima fica inconsciente devido a colisão de Kara com o planeta aritificial em que estavem. Então o Super-Homem tem que rastrear a Supergirl, onde quer que ela tenha ido. Superman calcula a trajetória de vôo de Supergirl e voa atrás dela. Para isto, remonta os fatos que antecedem o sumiço da prima. No final, com sua alta capacidade mnemonica, ele recorda o rumo dele e a encontra.

Numa perspectiva Catrogiana, ele utiliza a protomemória e, de repente, se dá conta de que, embora longe da moça, podia encontrá-la e assim achar o caminho de volta à realidade. Por isso questiona a si mesmo: "Por que perder tempo perguntando mesmo?... Eu não tenho realmente nenhuma escolha!”. Nesse processo, ele parte da protomemória para enfim chegar a memória. Este trecho de análise, evidencia que

a memória é a vida, sempre carregada por grupos vivos e, nesse sentido, ela está em permanente evolução, aberta à dialética da lembrança e do esquecimento, inconsciente de suas deformações sucessivas, vulnerável a todos os usos e manipulações, suscetível de longas latências e de repentinas revitalizações. (NORA, 1984, p. 19)

O Homem de Aço possui vários superpoderes ${ }^{31}$, três deles são associados à memória: a Memória Eidética, o Hipnotismo e o Beijo do Esquecimento. O primeiro superpoder permite que ele armazene, restaure e acesse informações e posteriormente utilize-as para salvar aqueles estão em perigo. $\mathrm{O}$ segundo permite que ele modifique, apague, crie e/ou implante informações que possam ser guardadas pela memória. Já o

(QUADRO 2) Feito! / Quer experimentar, Homem-aranha? / Já pensou em animar festinhas e baile de debutantes com seu talento? / Com seu talento você faria fortuna].

30 Superman vs. Espectro: “where no Superman has gone before!", número 29, 1981, p 05.

Disponivel em: <https://bit.ly/2NCiSFC>. Acesso: nov-2018.

31 QUINTAS, Francisco. Fique por dentro de TODOS os poderes do Superman!, 2018. Disponível em: <https://bit.ly/30DGzBn>. Acesso: dez-2018. 


\section{VOZES $_{\text {\&IÁLORO }}^{\mid}$}

Itajaí, v. 18, n. 02, jul/dez 2019

terceiro possibilita absorver, bloquear ou apagar informações e fatos ocorridos da memória dos demais personagens que presentes na trama.

Tanto o Hipnotismo quanto o Beijo do Esquecimento são utilizados pelo herói todas as vezes em que sua identidade dupla está ameaçada. São estratégias para salvaguardar sua personalidade secreta, possibilitando que o Homem de Aço manipule a memória de outros. O Hipnotismo, a título de exemplo, foi utilizado na hq número 330, de 1978. Mesmo tendo se ausentado do local, Clark não tem seu sumiço notado por ninguém, pois neste episódio

Martin Pasko (roteiros) e Curt Swan (arte) resolveram mostrar que os óculos de Clark tinham lentes feitas com vidro do foguete que trouxe ele de Krypton para a Terra. Elas intensificavam um efeito hipnótico em seus olhos, fazendo com que as outras pessoas enxergassem uma imagem projetada do pacato jornalista. (NALIATO, 2015. sp.)

\section{Considerações finais}

Assim como com o protagonista desta pesquisa, a sedução da memória deixou o âmbito literário-ficcional para consubstanciar-se na vida real: os 'Cristais de memória do Superman $^{32}$ agora são reais. Desse modo, a arte não só imita vida, mas é a própria vida: a realidade literária, ficcional é agora uma realidade histórica, um dado da história humana. Os mortais poderão experimentar ter a condição mnemônica, mesmo que indiretamente, do herói americano ao utilizar os tais cristais. O personagem estadunidense atinge dessa forma um além da realidade, uma hiper-realidade, na qual fica evidente que "a imaginação norte-americana deseja a coisa verdadeira e para atingi-la deve realizar o falso absoluto; e onde as fronteiras entre o jogo e a ilusão se confundem, o museu de arte é contaminado pela tenda das maravilhas, e a mentira é saboreada numa situação de "pleno" de horror vacui" (ECO, 1984, p. 14).

Agora a humanidade pode exorcizar o fantasma do esquecimento, poderemos deixar nossas lembranças para posteridade sem qualquer preocupação, pois os 'cristais do Superman’ podem armazenar 360TB por 1 milhão de anos, conforme os cientistas que o criaram. ${ }^{33}$ Enfim, à moda americana poderemos acessar a memória de nossos predecessores sem que se quer precisemos fazer o exercício mental da recordação, pois a memória passa assim a ser concebida como

\footnotetext{
${ }^{32}$ Criado em 2013 por cientistas da Universidade de Southampton. Pete Kazansky, supervisor da equipe, destaca que é "emocionante pensar que foi criado o primeiro 'documento' capaz de sobreviver à raça humana". Segundo ele, "esta tecnologia pode armazenar as últimas evidências da civilização: tudo o que foi aprendido não será esquecido". In: Terra, "Cristais de memória do Superman" armazenam até 360TB por 1 milhão de anos, 2013.Disponível em: <https://bit.ly/2Lg9gh2>. Acesso: dez-2018.

${ }^{33}$ Cristais de memória do Superman" armazenam até 360TB por 1 milhão de anos, 2013.Disponível em: < https://bit.ly/2Zj4w4d>. Acesso: dez-2018.
} 


\section{VOZES $_{\text {\&IÁLORO }}^{\mid}$}

Itajaí, v. 18, n. 02, jul/dez 2019

[...] a capacidade de adquirir, armazenar e recuperar informações disponíveis tanto no cérebro como em outros mecanismos artificiais como, por exemplo (sic) a memória de um computador, ou nos documentos de arquivo. [...] É através dela que damos significado ao cotidiano. (PEREIRA, 2011, p. 23)

Talvez, nossos sucessores possam responder às indagações de Mário Quintana que abrem este trabalho: "Essa lembrança...mas de onde? de quem?" Agora nem texto escrito nem imagens como via de acesso à memória, agora a memória está 'coisificada' num "HD gigante”. Ela é um documento, como bem ratificou Bloch "o passado é, por definição, um dado que nada mais modificará. Mas o conhecimento do passado é uma coisa em progresso, que incessantemente se transforma e se aperfeiçoa” (BLOCH, 2002, p. 26). Os 'Cristais de memória do Superman' ratificam um alerta de Marc Bloch, feito ainda no século passado, o de que "é uma grande ilusão imaginar que cada problema histórico corresponde a um tipo único de documento” (BLOCH, 2002, p. 27).

Por hora somos levados a crer que "toda a evolução do mundo contemporâneo, sob a pressão da história imediata em grande parte fabricada ao acaso pelo media, caminha em direção a um mundo acrescido de memórias coletivas e a história estaria, muito mais que antes ou recentemente, sob pressão dessas memórias coletivas” (LE GOFF, 1990, p. 473). Que este pontual exercício estimule outros pesquisadores a pensarem, de modo mais amplo, a relação entre $\mathrm{HQ}^{\prime}$ s, memória e história.

\section{Referências}

BAKHTIN, Mikhail. (1926) Le discours dans la vie et dans la poésie. In: TODOROV, Tzvetan. Mikhail Bakhtine: le príncipe dialogique. Paris: Éditions Du Seuil, 1981.

BAKHTIN, Mikhail; VOLOSHINOV, Valentin. Marxismo e filosofia da linguagem. São Paulo: Hucitec, 2006.

BLOCH, Marc. Apologia da História ou Ofício do Historiador. Rio de Janeiro, Zahar, 2002.

CALLARI, Alexandre. Quadrinhos no cinema 3: O guia completo dos super-heróis. São Paulo: Editora Évora, 2013.

CATROGA, Fernando. Memória e História. In: PESAVENTO, Sandra (Org.). Fronteiras do milênio. Porto Alegre: UFRGS, 2001.

CERTEAU, Michel de. A Escrita da história. Tradução de Maria de. Lourdes Menezes. Rio de Janeiro: Forense Universitária, 1982. 


\section{VOZES $_{\text {\&DÁLORO }}^{\mid}$}

Itajaí, v. 18, n. 02, jul/dez 2019

CHAGAS, Mário. Memória e Poder: dois movimentos. Cadernos de Sociomuseologia, [S.l.], v. 19, n. 19, junho 2009, p. 67. ISSN 1646-3714. Disponível em: <https://bit.ly/2MIGYPG>. Acesso: dez-2018.

CHARTIER, Roger. A história cultural: entre práticas e representações. Rio de Janeiro: Bertrand Brasil, 1990.

CIRNE, Moacy. A Explosão Criativa nos Quadrinhos. Petrópolis: Editora Vozes, 1974.

CIRNE, Moacy. Uma introdução política aos quadrinhos. Rio de Janeiro: Achiamé/Angra, 1982.

COLTON, David. História do Super-homem: Um roubo fatal forjou o Homem de Aço?, 2008. Disponível em: <https://bit.ly/2NyvEVE> Acesso: nov-2018.

DORFMAN, Ariel; JOFRÉ, Manuel. Super-homem e seus amigos do peito. Rio de Janeiro: Paz e Terra, 1978.

ECO, Umberto. Viagem na irrealidade cotidiana. Rio de Janeiro: Nova Fronteira, 1984.

GAIARSA, José A. Desde a pré-história até McLuhan. In: MOYA, Álvaro de. SHAZAM. São Paulo: Editora Perspectiva, 1977.

HOBSBAWN, Eric. Era dos Extremos: O breve século XX (1914-1991). Tradução de Marcos Santarrita. São Paulo: Companhia das Letras, 1995.

HUGHES-HALLETT, Lucy. Heróis: salvadores, traidores e super-homens. Rio de Janeiro: Record, 2007.

JONES, Gerard. Homens do Amanhã. Tradução de Guilherme da Silva Braga e Beth Vieira]. São Paulo: Conrad Editora do Brasil, 2006.

KNOWLES, Christopher. Nossos deuses são super-heróis: a história secreta dos superheróis das histórias em quadrinhos. São Paulo: Cultrix, 2008.

LE GOFF, Jacques. História e Memória. Campinas: Editora da Unicamp, 1990.

LIMA, Diego. Milésima Edição da ActionComic comemora os 80 anos de Superman, 2018. Publicada em 18 de abril de 2018. Disponível em: 〈https://bit.ly/2ZuKxyW〉. Acesso: nov-2018.

MAINGUENEAU, Dominique. A propósito do ethos. In: MOTTA, Ana Raquel \& SALGADO, Luciana, (orgs.). Ethos discursivo. São Paulo: Contexto, 2008

MANNING, Matthew. K. Os arquivos Secretos do Home de Aço. Tradução de Dandara Palankof. EUA: Editora Andrews McMeel, 2017. 


\section{VOZES $_{\text {\&IÁLORO }}^{\mid}$}

Itajaí, v. 18, n. 02, jul/dez 2019

MENESES, Ulpiano T. Bezerra de. Fontes visuais, cultura visual, história visual: balanço provisório, propostas cautelares. Rev. Bras. Hist. São Paulo, v. 23, n. 45, p. 11-36, julho de 2003. Disponível em: <https://bit.ly/2Zm0HLB>. Acesso: dez-2018.

NALIATO, Samir. Dez poderes bizarros do Superman, 2015. Disponível em: <https://bit.ly/2PkJQnK>. Acesso: dez-2018.

NORA, Pierre. " Entre mémoire et histoire: la problematique des lieux ». In: GERON, Charles-Robert. (org). Le lieux de mémoire. Paris: Gallimard, 1984.

PEREIRA, Fernanda Cheiran. Arquivos, memória e justiça: Gestão documental e preservação de acervos judiciais no Rio Grande do Sul. Orientação de Jorge Eduardo Enriquez Vivar. Porto Alegre, 2011. Trabalho de Conclusão de Curso (Graduação). Universidade Federal do Rio Grande do Sul. 173 f. Disponível em: <https://bit.ly/2LfOYVb>. Acesso: nov-2018.

QUINTANA, Mário. Essa Lembrança que nos vem. In: Antologia Poética. Porto Alegre: L\&M, 1997.

ROBB, Brian J. A identidade secreta dos super-heróis: a história e as origens dos maiores sucessos das HQ's: do super-homem aos vingadores. Rio de Janeiro: Valentina, 2017.

ROTHBARD, Murray Newton. A Grande Depressão Americana. Tradução de Pedro Sette-Câmara. Mises: Brasil, 2012.

SCOTT, Cord A. Comics and Conflict: War and Patriotically Themed Comics in American Cultural History From World War II Through the Iraq War. Dissertation (Doctor of Philosophy) - Loyola University Chicago. Chicago, 2011. Disponível em: $<$ https://bit.ly/32a0aJD $\geq$. Acesso: dez-2018.

WELDON, Glen. A Biografia não autorizada do Superman. Tradução de Débora Guimarães Isidoro. São Paulo: Leya, 2016. 